\title{
The observation of nitric acid-containing particles in the tropical lower stratosphere
}

\author{
P. J. Popp ${ }^{1,2}$, T. P. Marcy ${ }^{1,2}$, E. J. Jensen ${ }^{3}$, B. Kärcher ${ }^{4}$, D. W. Fahey ${ }^{1}$, R. S. Gao ${ }^{1}$, T. L. Thompson ${ }^{1}$, K. H. Rosenlof ${ }^{1}$, \\ E. C. Richard ${ }^{1,2, *}$, R. L. Herman ${ }^{5}$, E. M. Weinstock ${ }^{6}$, J. B. Smith ${ }^{6}$, R. D. May $^{7}$, H. Vömel ${ }^{8}$, J. C. Wilson ${ }^{9}$, \\ A. J. Heymsfield ${ }^{10}$, M. J. Mahoney ${ }^{5}$, and A. M. Thompson ${ }^{11}$ \\ ${ }^{1}$ Chemical Sciences Division, Earth System Research Laboratory, National Oceanic and Atmospheric Administration, \\ Boulder, CO 80305, USA \\ ${ }^{2}$ Cooperative Institute for Research in Environmental Sciences, University of Colorado, Boulder, CO 80309, USA \\ ${ }^{3}$ NASA Ames Research Center, Moffett Field, CA 94035, USA \\ ${ }^{4}$ Institut für Physik der Atmosphäre, Deutsches Zentrum für Luft- und Raumfahrt, Oberpfaffenhofen, Germany \\ ${ }^{5}$ Jet Propulsion Laboratory, California Institute of Technology, Pasadena, CA 91109, USA \\ ${ }^{6}$ Atmospheric Research Project, Harvard University, Cambridge, MA 02138, USA \\ ${ }^{7}$ MayComm Instruments, San Dimas, CA 91773, USA \\ ${ }^{8}$ Global Monitoring Division, Earth System Research Laboratory, National Oceanic and Atmospheric Administration, \\ Boulder, CO 80305, USA \\ ${ }^{9}$ Department of Engineering, University of Denver, Denver, CO 80208, USA \\ ${ }^{10}$ Mesoscale and Microscale Meteorology Division, National Center for Atmospheric Research, Boulder, CO 80301, USA \\ ${ }^{11}$ Department of Meteorology, Pennsylvania State University, University Park, PA 16802, USA \\ *now at: Laboratory for Atmospheric and Space Physics, University of Colorado, Boulder, CO 80303, USA
}

Received: 9 August 2005 - Published in Atmos. Chem. Phys. Discuss.: 18 October 2005

Revised: 18 January 2006 - Accepted: 18 January 2006 - Published: 27 February 2006

\begin{abstract}
Airborne in situ measurements over the eastern Pacific Ocean in January 2004 have revealed a new category of nitric acid $\left(\mathrm{HNO}_{3}\right)$-containing particles in the tropical lower stratosphere. These particles are most likely composed of nitric acid trihydrate (NAT). They were intermittently observed in a narrow layer above the tropopause $(18 \pm 0.1 \mathrm{~km})$ and over a broad geographic extent $(>1100 \mathrm{~km})$. In contrast to the background liquid sulfate aerosol, these particles are solid, much larger (1.7-4.7 $\mu \mathrm{m}$ vs. $0.1 \mu \mathrm{m}$ in diameter), and significantly less abundant $\left(<10^{-4} \mathrm{~cm}^{-3}\right.$ vs. $\left.10 \mathrm{~cm}^{-3}\right)$. Microphysical trajectory models suggest that the NAT particles grow over a 6-14 day period in supersaturated air that remains close to the tropical tropopause and might be a common feature in the tropics. The small number density of these particles implies a highly selective or slow nucleation process. Understanding the formation of solid NAT particles in the tropics could improve our understanding of stratospheric nucleation processes and, therefore, dehydration and denitrification.
\end{abstract}

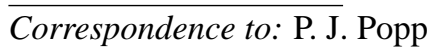

(peter.j.popp@noaa.gov)

\section{Introduction}

The nucleation and growth of ice and other solid-phase particles in the upper troposphere and lower stratosphere affect chemical composition and climate forcing (Baker, 1997; Lawrence et al., 1998; McFarquhar et al., 2000; Jensen and Pfister, 2004). Ice formation in the tropopause region regulates stratospheric humidity through particle sedimentation and controls the radiative properties of high clouds (Jensen et al., 1996). Polar stratospheric clouds, when composed of NAT $\left(\mathrm{HNO}_{3} \cdot 3 \mathrm{H}_{2} \mathrm{O}\right)$, sediment and denitrify the lower stratosphere in winter and thereby enhance photochemical ozone destruction (Davies et al., 2005; Rex et al., 1997; Gao et al., 2001). Theoretical efforts have had limited success in identifying and quantifying atmospheric nucleation processes, in part, because of incomplete knowledge of aerosol composition and how composition affects nucleation. This in turn limits our current understanding of how global change might alter future cloudiness, stratospheric dehydration, and ozone amounts.

Published by Copernicus GmbH on behalf of the European Geosciences Union. 


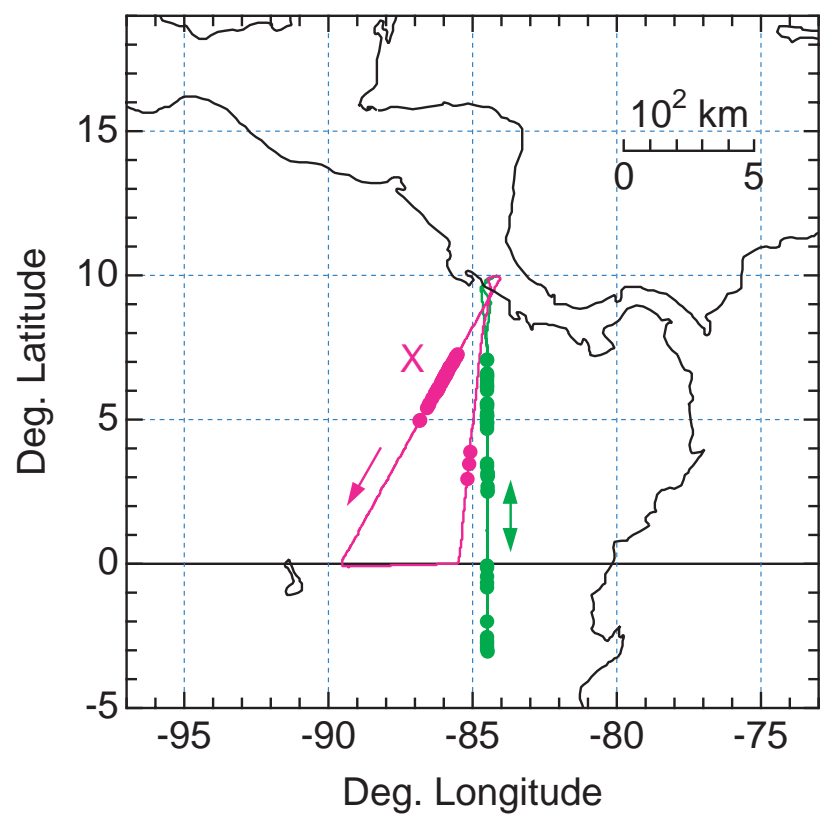

Fig. 1. Map of the WB-57F flight tracks on 27 (green) and 29 (purple) January 2004. Observations of individual $\mathrm{HNO}_{3}$-containing particles are indicated by solid symbols laid over the flight tracks. Both flights originated and terminated in San Jose, Costa Rica $\left(10^{\circ} \mathrm{N}, 84^{\circ} \mathrm{W}\right)$. The flight track segment on 29 January marked by " $\mathrm{X}$ " is the region of highest particle concentrations and corresponds to the purple bar in Fig. 2.

Observations of ambient aerosol from ground-based, airborne, and space-borne platforms under a wide range of conditions are providing key guidance in completing our understanding of microphysical processes. In situ observations made on airborne platforms are particularly effective because they offer high spatial resolution with quantitative detail, and as a consequence can be used to reveal features of atmospheric aerosol processes that would otherwise be inaccessible. An important example of the guiding role of observations is the discovery of large NAT particles in the Arctic winter stratosphere using airborne instruments (Fahey et al., 2001; Northway et al., 2002). Proof of their existence has led to a refined and more comprehensive view of how NAT particles denitrify the stratosphere and how atmospheric conditions can affect denitrification (Davies et al., 2005; Mann et al., 2003). However, the nucleation process for these large particles remains an unsolved microphysical puzzle.

Here we present evidence for a new category of NAT particles that nucleate and grow in the tropical lower stratosphere. The particles are only a small fraction of the ambient aerosol population, and they grow under substantially different conditions than those found in polar regions. First, gas-phase $\mathrm{HNO}_{3}$ values observed in the tropical lower stratosphere were typically $0.1 \mathrm{ppbv}$ or lower, which is 10 to 100 times less than that available for particle growth in the polar stratosphere. As a result, the growth times of NAT particles in the tropical lower stratosphere will generally be much longer than those of NAT particles in polar regions. Second, the particles grow at temperatures much closer to the frost point. In the tropics, NAT saturation conditions occur within $+1.5 \mathrm{~K}$ of the frost point while the difference can exceed $+6 \mathrm{~K}$ in the polar lower stratosphere. Third, the new particles grow over considerable horizontal distances (up to $15000 \mathrm{~km}$ ) in a narrow altitude range (a few hundred meters) near the tropopause where NAT saturation conditions are favorable. In polar regions, NAT growth can occur over a 5$10 \mathrm{~km}$ vertical extent confined to the low temperature region of the polar vortex.

\section{Particle detection}

The tropical NAT particles were detected in situ with a chemical ionization mass spectrometer (CIMS) onboard the NASA WB-57F high-altitude research aircraft. The CIMS instrument measures $\mathrm{HNO}_{3}$ with two independent channels of detection connected to separate forward- and downwardfacing inlets (Popp et al., 2004). The forward-facing inlet samples both gas- and particle-phase $\mathrm{HNO}_{3}$. Particles are inertially stripped from the air stream sampled by the downward-facing inlet, effectively yielding a measure of only gas-phase $\mathrm{HNO}_{3}$. Thus, the difference in the signal between the two channels allows a determination of the amount of $\mathrm{HNO}_{3}$ in the particle phase (Popp et al., 2004; Gao et al., 2004). When particle concentrations are low enough $\left(<\sim 10^{-3} \mathrm{~cm}^{-3}\right)$, individual $\mathrm{HNO}_{3}$-containing particles can be detected as peaks above the background gas-phase value in the time series of $\mathrm{HNO}_{3}$ measurements. The frequency of these peaks in the time series and the known particle sampling volume of the CIMS instrument directly yield the ambient particle concentration (Fahey et al., 2001).

$\mathrm{HNO}_{3}$-containing particles were observed on two flights over the eastern tropical Pacific Ocean in January 2004. The flights originated and ended in San Jose, Costa Rica, $\left(10^{\circ} \mathrm{N}\right)$ while reaching the Galapagos Islands $\left(1^{\circ} \mathrm{S}\right)$ or further south of the equator as shown in Fig. 1. Time series of observations and derived quantities for the flights are shown in Figs. 2 and 3. The most intense period of particle observations occurred on 29 January over a $300 \mathrm{~km}$ (30 min) flight segment (marked by $\mathrm{X}$ in Figs. 1 and 2). Individual $\mathrm{HNO}_{3}$-containing particles are identified in Fig. 2a as peaks throughout the segment. The detection of several individual particles is shown in Fig. 2e. During the $30 \mathrm{~min}$ interval, a total of 59 particles were observed, yielding an average particle concentration of $6 \cdot 10^{-5} \mathrm{~cm}^{-3}$. Lower particle concentrations were observed for a short period later on the same flight and for several periods during the flight on 27 January 2004 (Fig. 3). Overall, particles were found over a narrow range of flight altitudes $(18 \pm 0.1 \mathrm{~km})$ and temperatures $(190 \pm 2 \mathrm{~K})$, and intermittently over a broad geographic extent $(1100 \mathrm{~km})$ between $3^{\circ} \mathrm{S}$ and 

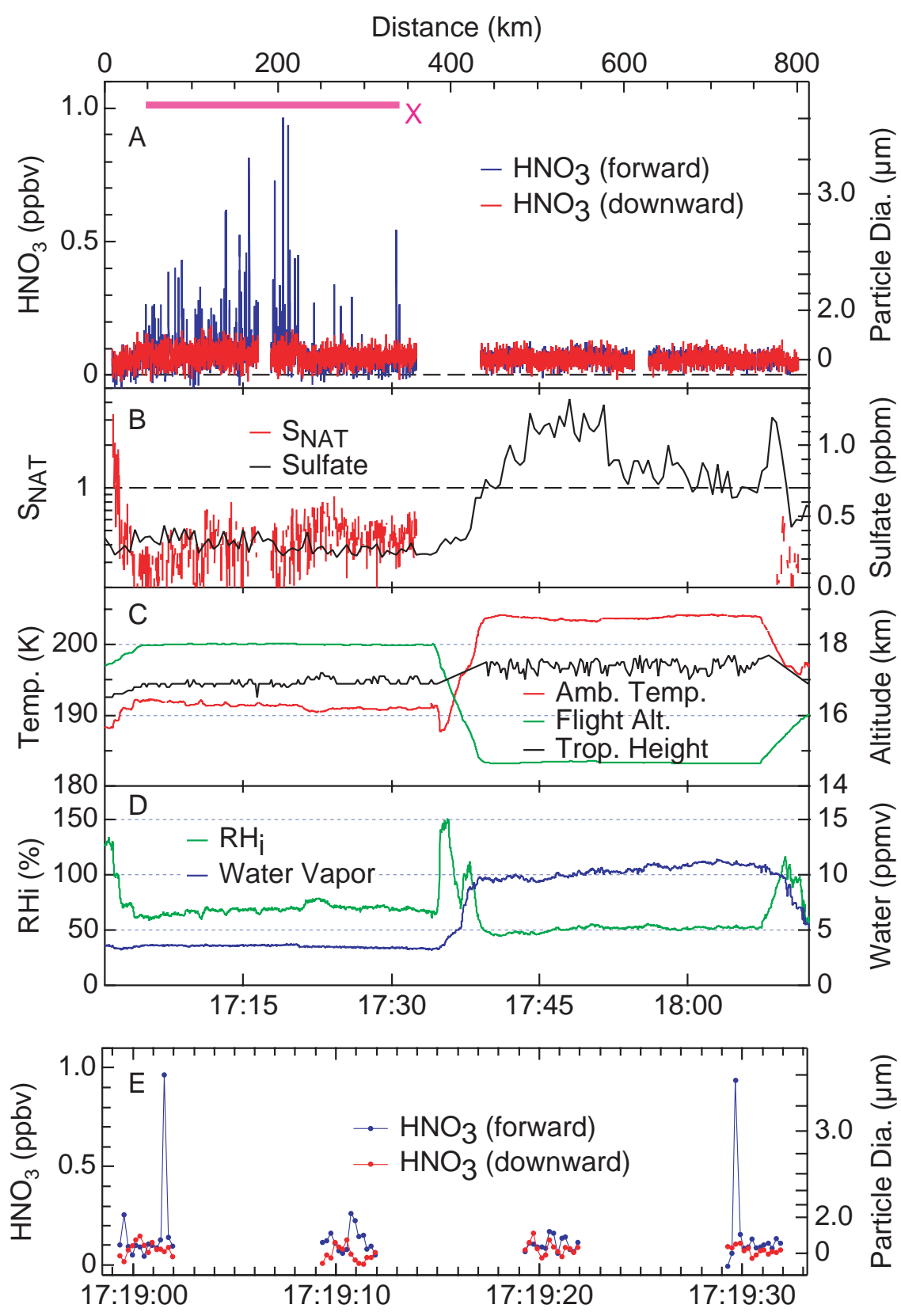

Universal Time

Fig. 2. Time series measurements of the $\mathrm{HNO}_{3}$ mixing ratios observed from the forward- and downward-facing CIMS channels (blue and

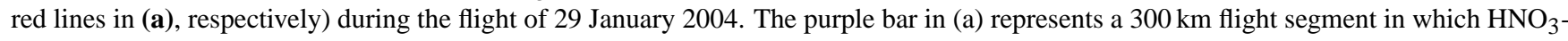
containing particles were observed and corresponds to region X in Fig. 1. Also shown are calculated values of $S_{\mathrm{NAT}}$ and measured sulfate mass mixing ratios (panel (b)); ambient temperature, flight altitude and cold-point tropopause height (panel (c)); and measured water vapor and calculated values of relative humidity with respect to ice $\left(R H_{i}\right)$ (panel (d)). Panel (e) is a 35-s flight segment expanded from panel (a) that shows $\mathrm{HNO}_{3}$-containing particles as peaks in forward-facing CIMS channel (blue line) and the absence of peaks in the downwardfacing CIMS channel (red line). The $\mathrm{HNO}_{3}$ measurements are shown at $5 \mathrm{~Hz}$ in both (a) and (e). Assuming the $\mathrm{HNO}_{3}$-containing particles are composed of NAT, the spherical-equivalent diameter of the particles is $\mathrm{D}(\mu \mathrm{m})=6.0\left[\mu \mathrm{HNO}_{3}\right]^{1 / 3}$ where $\mu \mathrm{HNO}_{3}$ is the integrated $\mathrm{HNO}_{3}$ mixing ratio for an individual particle in ppbv.s. The calculated particle diameters are shown on the right axes in (a) and (e). The gap in the $\mathrm{HNO}_{3}$ data at $\sim 17: 16$ UT in (a) represents a 60-s instrument background measurement. The gaps in the $\mathrm{HNO}_{3}$ data in (e) occur when the instrument is monitoring the CIMS reagent ion, or the product ions used to measure hydrochloric acid $(\mathrm{HCl})$ or chlorine nitrate $\left(\mathrm{ClONO}_{2}\right)$. The $\mathrm{HNO}_{3}$ product ion is monitored for $3 \mathrm{~s}$ out of every 10 -s period, and derived particle concentrations account for this $30 \%$ duty cycle. Measurements other than $\mathrm{HNO}_{3}$ shown in Fig. 2 are described in Appendix B. 


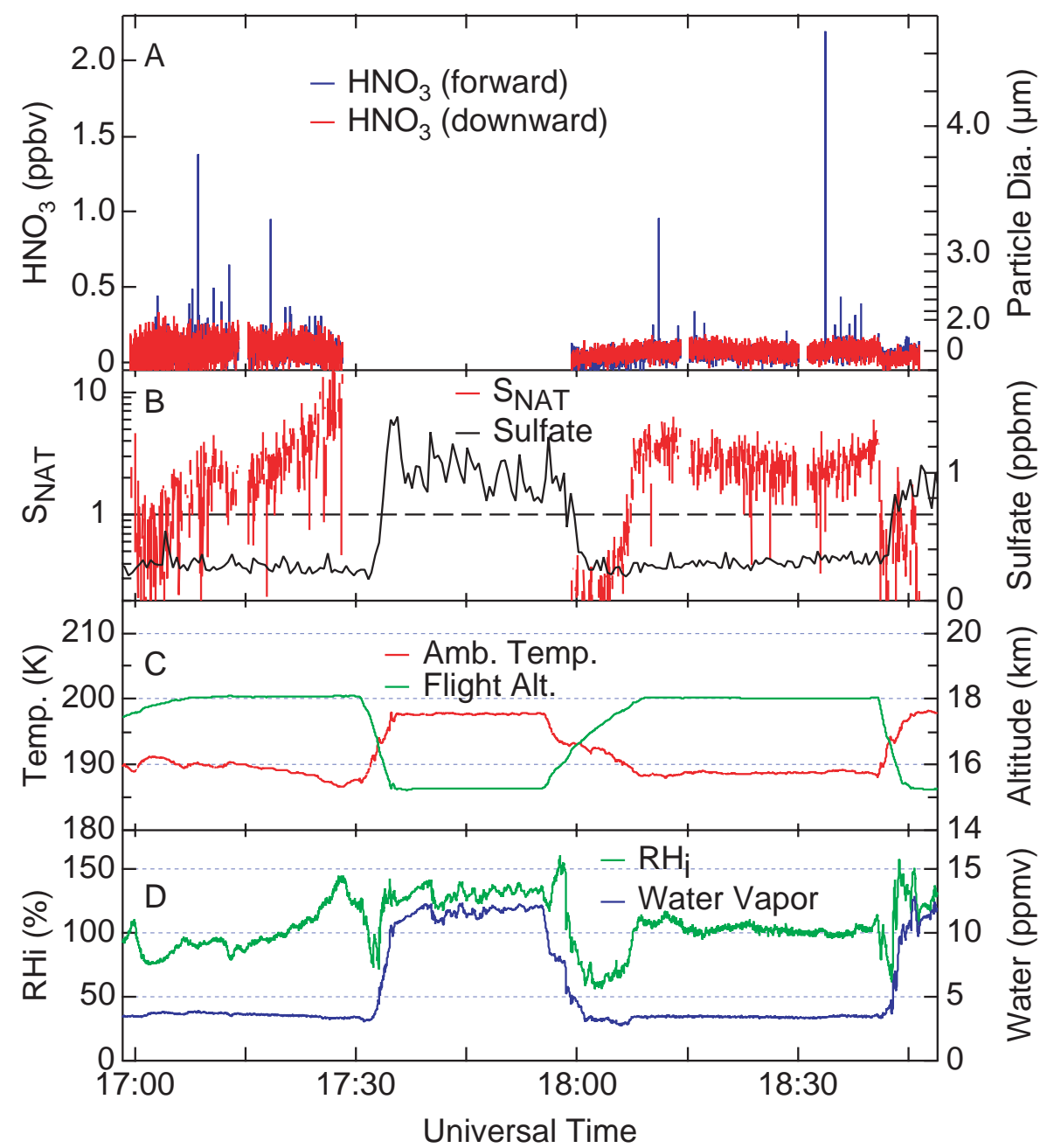

Fig. 3. Time series measurements of $\mathrm{HNO}_{3}$ mixing ratios observed from the forward- and downward-facing CIMS channels (blue and red lines in (a), respectively) on 27 January 2004. Also shown are calculated values of $\mathrm{S}_{\mathrm{NAT}}$ and measured sulfate mass mixing ratios (panel (b)); ambient temperature and flight altitude (panel (c)); and measured water vapor and calculated values of relative humidity with respect to ice $\left(R H_{i}\right)$ (panel (d)). The $\mathrm{HNO}_{3}$ measurements are shown at $5 \mathrm{~Hz}$ in (a). Tropopause height data was not available for this flight.

$7^{\circ} \mathrm{N}$ latitude. We note here that the particles were observed at the maximum flight altitude of the WB-57F $(18 \mathrm{~km})$, and it seems possible that the particles exist in a layer that extends to altitudes higher than $18 \mathrm{~km}$. Microwave temperature profiles show that the cold-point tropopause was typically 0.5 to $1 \mathrm{~km}$ below the observed particles (Fig. 2c). The two halves of the time series in Fig. 2 contrast the flight segment where particles are detected with one of similar length at lower altitude. The latter shows no evidence of particles and further shows the agreement between the two CIMS detection channels in the absence of $\mathrm{HNO}_{3}$-containing particles. Additional evidence for the presence of $\mathrm{HNO}_{3}$-containing particles on 29 January (Fig. 2) is provided by an automatic check of the background signal of the CIMS instrument. The background signal is checked at regular intervals during flight by adding a flow of dry nitrogen to the sample line $6 \mathrm{~cm}$ from the inlet opening. The nitrogen flow is large enough that a fraction flows out of the inlet opening, thereby preventing ambient gases or small particles from entering the inlet (Neuman et al., 2000; Popp et al., 2004). This automatic check is the cause of the 1-min gap near 17:16 UT in the time series in Fig. 2. Peaks were not observed during this period, but were observed in each of several 1-min periods before and after the background check. This result is consistent with particles entering the forward-facing inlet being the cause of the peaks found in the forward CIMS channel.

\section{Particle composition and size}

We assume the composition of the sampled particles to be NAT. NAT is the most stable $\mathrm{HNO}_{3}$ condensate at the observed levels of $\mathrm{HNO}_{3}$ and water vapor, and is known to form at low temperatures in the polar winter stratosphere (Voigt et al., 2000). The observed particles are unlikely to be 
a supercooled ternary solution (STS) composed of $\mathrm{H}_{2} \mathrm{SO}_{4}$, $\mathrm{HNO}_{3}$, and water, or ice particles containing $\mathrm{HNO}_{3}$ on the surface or in the bulk. Results from the Aerosol Inorganics Model (Carslaw et al., 1995) indicate that formation of STS via uptake of $\mathrm{HNO}_{3}$ by the background aerosol population is not thermodynamically favorable at temperatures greater than approximately $186 \mathrm{~K}$ with observed amounts of $\mathrm{HNO}_{3}$, sulfate, and water vapor. Furthermore, since there is no thermodynamic nucleation barrier to the uptake of $\mathrm{HNO}_{3}$ by the background sulfate aerosol, all available aerosols would grow to form STS. The concentration of the resulting STS population, therefore, would be equivalent to that of the background sulfate aerosol $\left(\sim 10 \mathrm{~cm}^{-3}\right)$ and approximately $10^{5}$ times greater than the particle population reported here.

While cirrus ice particles have been observed to contain $\mathrm{HNO}_{3}$ in the upper troposphere and lower stratosphere (Kondo et al., 2003; Popp et al., 2004) the particles described in this study are unlikely to be composed of ice. Using $\mathrm{HNO}_{3}$ contents typical of those observed in subtropical cirrus cloud particles (Popp et al., 2004), ice particles would need to be at least 50 to $200 \mu \mathrm{m}$ in diameter to produce an instrument response similar to that shown in Figs. 2 and 3. These ice particle sizes represent lower limits, since $\mathrm{HNO}_{3}$ uptake by ice particles is proportional to the gas-phase partial pressure of $\mathrm{HNO}_{3} \cdot \mathrm{HNO}_{3}$ partial pressures in the subtropical cirrus clouds were 5-10 times greater than those observed in the tropical lower stratosphere during this study (Popp et al., 2004). The Video Image Particle Sampler (VIPS), which detects particles above $\sim 10 \mu \mathrm{m}$ in diameter (Heymsfield and McFarquhar, 1996), observed no significant evidence for a population of large ice particles coincident with the CIMS particle observations. Furthermore, there was no observable ice water content in these air masses $(<1 \mathrm{ppmv})$. Ice water content is measured as the difference between the total water and water vapor measurements onboard the aircraft (Weinstock et al., 1994 and Appendix B).

We also note that the particles observed in this study are distinctly different from ultrathin tropical tropopause cloud (UTTC) particles first observed over the western Indian Ocean (Peter et al., 2003; Luo et al., 2003). While UTTC particles are only slightly larger than the NAT particles reported here ( $\sim 10 \mu$ m mode diameter), they are composed of ice, are more concentrated than the NAT particles by 2 to 3 orders of magnitude $\left(\sim 10^{-2} \mathrm{~cm}^{-1}\right)$, and were observed below the cold-point tropopause exclusively. UTTCs are stabilized in a thin layer below the tropopause by an upwelling velocity that maintains supersaturation with respect to ice above the cloud and subsaturation below the cloud. This mechanism limits UTTC particle sizes to less than $\sim 50 \mu \mathrm{m}$ in diameter. Adiabatic cooling events can destabilize the UTTCs by the formation of larger particles that sediment from the cloud layer and evaporate. Thus, UTTC particles cannot grow large enough to contain $\mathrm{HNO}_{3}$ amounts comparable to the NAT particles observed here.
With NAT composition assumed, calculated particle diameters are shown with the right hand axes in Figs. 2a and e. When all particles are examined from both flights, sizes range from 1.7 to $4.7 \mu \mathrm{m}$ in diameter. There is essentially no size dependence in the particle number distribution. Particles substantially larger than $4.7 \mu \mathrm{m}$ would be detected if present. The lowest observed size is set by the signal to noise ratio of the $\mathrm{HNO}_{3}$ measurements. Although it is likely that some NAT particles are present with sizes less than $1.7 \mu \mathrm{m}$, it is unlikely that their concentration would be significantly greater than $6 \cdot 10^{-5} \mathrm{~cm}^{-3}$. If a considerable number of smaller particles were present, they would deplete gas-phase $\mathrm{HNO}_{3}$ and preclude the growth of the larger observed particles in a reasonable amount of time.

In previous studies in which the CIMS instrument detected $\mathrm{HNO}_{3}$-containing particles, independent observations of particle size were available (Popp et al., 2004; Gao et al., 2004). During these studies, contrail particles with sizes of 1 to $3 \mu \mathrm{m}$ diameter were found to contain $\mathrm{HNO}_{3}$. These earlier observations confirm that particles greater than $\sim 1 \mu \mathrm{m}$ are inertially removed from the sample entering the downwardfacing CIMS inlet. In the present study, this lower size limit is consistent with the absence of peaks in the downwardfacing channel during periods when the forward-facing channel was detecting NAT particles with inferred sizes of 1.7$4.7 \mu \mathrm{m}$.

It is worth noting here that the CIMS instrument is capable of measuring hydrochloric acid $(\mathrm{HCl})$ and chlorine nitrate $\left(\mathrm{ClONO}_{2}\right)$ in addition to $\mathrm{HNO}_{3}$ (Marcy et al., 2005). During flight, the CIMS instrument measures $\mathrm{HNO}_{3}$ for $3 \mathrm{~s}$ out of every 10 -s period. The remaining $7 \mathrm{~s}$ are devoted to measuring $\mathrm{HCl}$ and $\mathrm{ClONO}_{2}$ for $3 \mathrm{~s}$ each, and to monitoring the CIMS reagent ion for $1 \mathrm{~s}$. Thus, $\mathrm{HNO}_{3}, \mathrm{HCl}$ and $\mathrm{ClONO}_{2}$ are observed for an equal amount of time during flight, and particles were sampled during the $\mathrm{HCl}$ and $\mathrm{ClONO}_{2}$ measurements modes at a rate equivalent to that during the $\mathrm{HNO}_{3}$ mode. No peaks in the $\mathrm{HCl}$ or $\mathrm{ClONO}_{2}$ time series were observed during the flights of 27 and 29 January 2004, indicating that neither species is present in the observed particles in amounts comparable to $\mathrm{HNO}_{3}$.

\section{NAT saturation conditions}

The formation of tropical NAT particles requires growth under NAT supersaturated conditions $\left(\mathrm{S}_{\mathrm{NAT}}>1\right.$, where $\mathrm{S}_{\mathrm{NAT}}$ is the ratio of available $\mathrm{HNO}_{3}$ to the equilibrium value over an NAT surface) (Hanson and Mauersberger, 1988). Using observed $\mathrm{HNO}_{3}$, water vapor, and temperature values, only some of the particles reported here were found in NAT supersaturated air. For example, during the most intense sampling period (Fig. 2), conditions were subsaturated with respect to NAT. This is not unusual since $\mathrm{HNO}_{3}$-containing particles and ice have been extensively observed in subsaturated air masses (Northway et al., 2002; Ström et al., 2003). This 


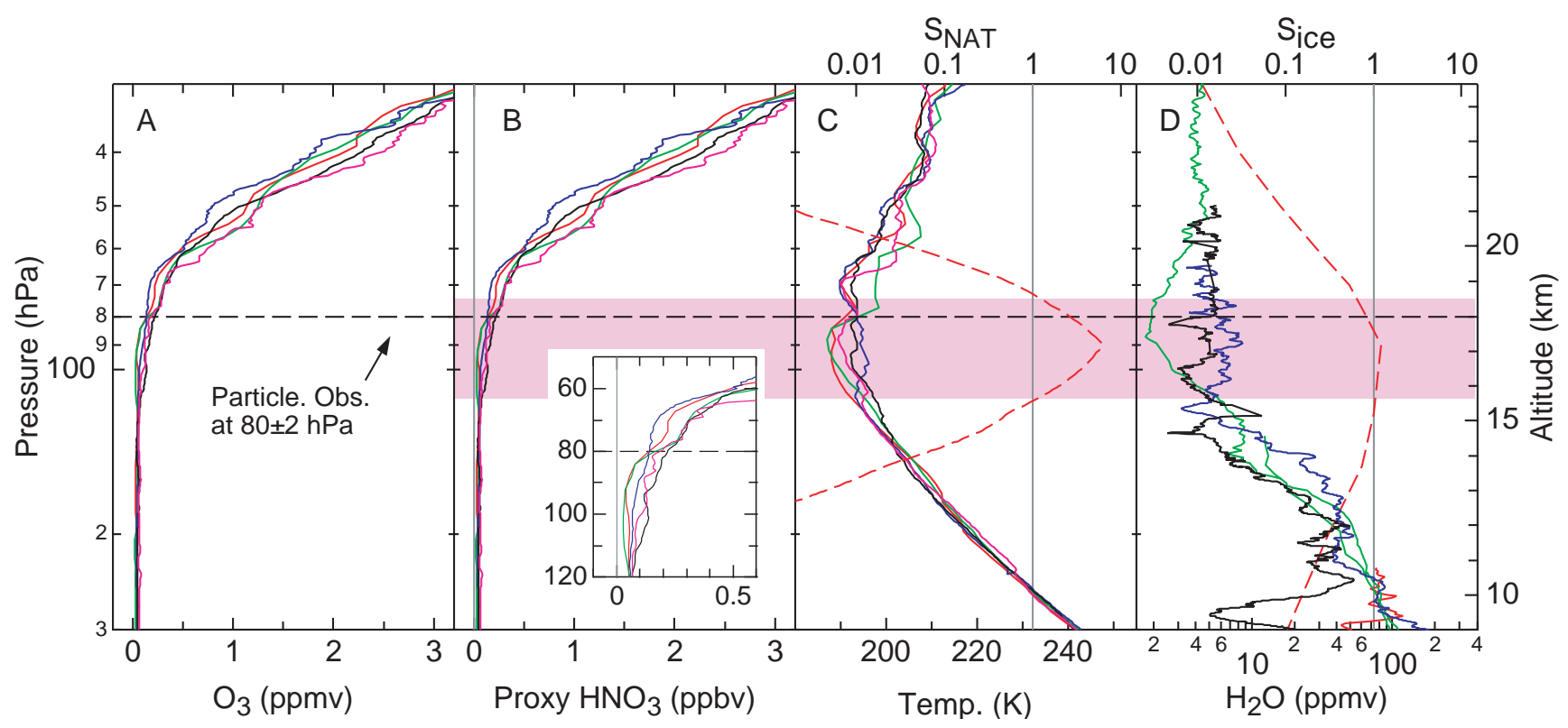

Fig. 4. Vertical profiles of ozone $\left(\mathrm{O}_{3}\right)(\mathbf{a})$, proxy $\mathrm{HNO}_{3}(\mathbf{b})$, temperature (c), and water vapor $\left(\mathrm{H}_{2} \mathrm{O}\right)$ (d) from balloon sonde measurements. Data in (a-c) were obtained on launches from San Cristóbal, Ecuador $\left(1^{\circ} \mathrm{S}, 90^{\circ} \mathrm{W}\right)$ on 23 and 30 January 2003 and $30 \mathrm{January} 2004$ (red, green and blue lines) or Paramaribo, Suriname $\left(6^{\circ} \mathrm{N}, 55^{\circ} \mathrm{W}\right)$ on 23 and 30 January 2003 (black and purple lines) from the Southern Hemisphere ADditional Ozonesonde (SHADOZ) network (Thompson et al., 2004). Data shown in (d) were obtained on launches from San Cristóbal on 29 and 30 January 2004 (red and green lines) or San Jose, Costa Rica $\left(10^{\circ} \mathrm{N}, 84^{\circ} \mathrm{W}\right)$ on 27 and 29 January 2004 (blue and black lines). We note that the water vapor data measured from San Cristóbal (red and green lines in (d)) was measured using a frostpoint hygrometer, which typically reports values $\sim 30 \%$ lower than the in situ instruments onboard the WB-57F (Kley et al., 2000). Proxy $\mathrm{HNO}_{3}$ profiles were derived from $\mathrm{O}_{3}$ values assuming a $\mathrm{HNO}_{3} / \mathrm{O}_{3}$ ratio of 0.001 . The purple region represents the altitude range in which $\mathrm{NAT}$ is stable $\left(\mathrm{S}_{\mathrm{NAT}}>1\right)$, calculated using the median values of $\mathrm{HNO}_{3}$, temperature and water vapor. The red dashed lines in $(\mathrm{c})$ and $(\mathrm{d})$ represent $\mathrm{S}_{\mathrm{NAT}}$ and $\mathrm{S}_{\text {ice }}$ profiles, respectively, also calculated using the median values of $\mathrm{HNO}_{3}$, temperature and water vapor. The black dashed line indicates the pressure at which particles were observed on the WB-57F flights on 27 and 29 January 2004.

apparent inconsistency potentially can be explained in two ways. First, the sampled particles are not necessarily in equilibrium with observed ambient conditions. As conditions change from supersaturated to subsaturated, NAT particles will begin to reduce in size, but do so slowly. For example, a 3- $\mu \mathrm{m}$ particle requires 5-7 days to completely sublimate at temperatures $1-2 \mathrm{~K}$ greater than $\mathrm{T}_{\mathrm{NAT}}$. Second, there is uncertainty in the observed parameters used in the NAT saturation calculation. $\mathrm{HNO}_{3}$ vapor in equilibrium with NAT is reduced by half if the temperature is decreased by $1 \mathrm{~K}$ or if water vapor is increased by $20 \%$. Uncertainties in the temperature, water, and $\mathrm{HNO}_{3}$ measurements, and the $\mathrm{HNO}_{3}$ $\mathrm{H}_{2} \mathrm{O}$ phase diagram, are such that the uncertainty in calculated $\mathrm{S}_{\mathrm{NAT}}$ values includes unity throughout the highlighted region in Fig. 2.

In situ measurements of $\mathrm{HNO}_{3}$ have not been reported previously for the tropical upper troposphere or lower stratosphere. As a consequence, in order to derive a representative vertical profile of NAT saturation conditions in the tropics, we use balloon sonde measurements of water and ozone and previous aircraft observations of the reactive nitrogen $\left(\mathrm{NO}_{\mathrm{y}}\right)$ to ozone ratio. $\mathrm{HNO}_{3}$ generally accounts for up to $80 \%$ of the
$\mathrm{NO}_{\mathrm{y}}$ reservoir in the lower stratosphere and is a smaller fraction in the upper troposphere (Neuman et al., 2001). Measurements in and near the tropics show that the $\mathrm{NO}_{\mathrm{y}} / \mathrm{O}_{3}$ ratio varies between 0.001 and 0.003 in the lower stratosphere, with the lower values found throughout the inner tropics (Murphy et al., 1993). These ratios are consistent with a $\mathrm{HNO}_{3} / \mathrm{O}_{3}$ ratio of 0.001 observed in the lower stratosphere between $1^{\circ} \mathrm{S}$ and $7^{\circ} \mathrm{N}$ during the WB-57F flight on $30 \mathrm{Jan}$ uary 2004. Proxy $\mathrm{HNO}_{3}$ profiles for the tropical upper troposphere and lower stratosphere were calculated by scaling ozone profiles by 0.001 . Representative ozone profiles were obtained from balloon sondes launched from San Cristóbal, Ecuador $\left(1^{\circ} \mathrm{S}\right)$ and Paramaribo, Suriname $\left(6^{\circ} \mathrm{N}\right)$ in January of 2003 and 2004. Similarly, ice stability is calculated from water vapor mixing ratios obtained from several balloon sondes that were coordinated with the aircraft flights. The profiles for $\mathrm{O}_{3}$, proxy $\mathrm{HNO}_{3}$, temperature, water vapor, and the associated regions of NAT and ice saturation are shown in Fig. 4. The results in Fig. 4 indicate that a $3 \mathrm{~km}$ layer near the tropopause will be supersaturated with respect to NAT under typical conditions. Within the NAT layer, a narrower layer of ice saturation might also exist. These results suggest 
that even with the low observed $\mathrm{HNO}_{3}$ amounts, NAT particles could be expected to routinely form near the tropical tropopause. The existence and width of this tropical layer is sensitive to $\mathrm{HNO}_{3}$ and water vapor amounts, and temperature, as noted in an earlier study (Hamill and Fiocco, 1988). The NAT-supersaturated layer is narrow because of the steep gradients in the controlling variables. Above the layer, increases in temperature dominate increases in $\mathrm{HNO}_{3}$ in determining NAT saturation. Below the layer, the sharp fall in $\mathrm{HNO}_{3}$ amounts and increasing temperatures preclude NAT saturation.

\section{Particle growth and trajectory calculations}

Particle growth under NAT saturation conditions is governed by gaseous diffusion, the $\mathrm{HNO}_{3}$ deposition coefficient, and particle shape. With the assumption of static ambient conditions, calculations of the growth times for a $0.1 \mu \mathrm{m}$ diameter particle in the background aerosol to become a 2 or $3 \mu \mathrm{m}$ NAT particle are shown in Fig. 5. The growth model used here is described in Appendix A. For observed $\mathrm{HNO}_{3}$ values near $0.1 \mathrm{ppb}$, growth times are in the range 8-17 days when the temperature is below the saturation point. The temperature and water vapor dependences (not shown) are not strong. For the largest particles, however, a doubling of $\mathrm{HNO}_{3}$ approximately halves the growth time. Particle sedimentation rates, which vary strongly with size, are approximately $13 \mathrm{~m} \mathrm{day}^{-1}$ and $80 \mathrm{~m}^{-1 a y}{ }^{-1}$ for $1 \mu \mathrm{m}$ and $3 \mu \mathrm{m}$ diameter particles, respectively, at observation altitudes. Thus, net displacements for the largest particles over a continuous growth period are only hundreds of meters, which is the approximate depth of the typical NAT-stable layer above the particle observations (Fig. 4). It is worth noting here that a population of $3 \mu \mathrm{m}$ NAT particles with a number density of $6 \cdot 10^{-5} \mathrm{~cm}^{-3}$ contains the gas-phase equivalent of $2 \mathrm{pptv}$ $\mathrm{HNO}_{3}$ at $80 \mathrm{hPa}$. The nucleation and growth of such a dilute population of particles, therefore, does not significantly deplete gas-phase $\mathrm{HNO}_{3}$.

Back-trajectory calculations provide strong evidence that suitable conditions existed for prolonged NAT growth. Trajectories initiated at all particle observation locations show that air parcels were continuously at low latitudes and low temperatures near the tropopause for at least 6-14 days prior to sampling. The trajectories, which include particle growth and sedimentation, are extended backwards in time until a particle reaches a size near $0.1 \mu \mathrm{m}$ in order to locate the approximate nucleation location. A small upwelling velocity $\left(0.3 \mathrm{~mm} \mathrm{~s}^{-1}\right)$ characteristic of the tropopause region is also imposed on the trajectories, which serves to lower the sedimentation rate of the particles during the growth period. For observations under NAT-supersaturated conditions on 27 January (Fig. 3), the particle trajectories show that particles nucleated at slightly higher altitudes between 6 and 14 days prior to sampling, and in some cases traveled over $15000 \mathrm{~km}$

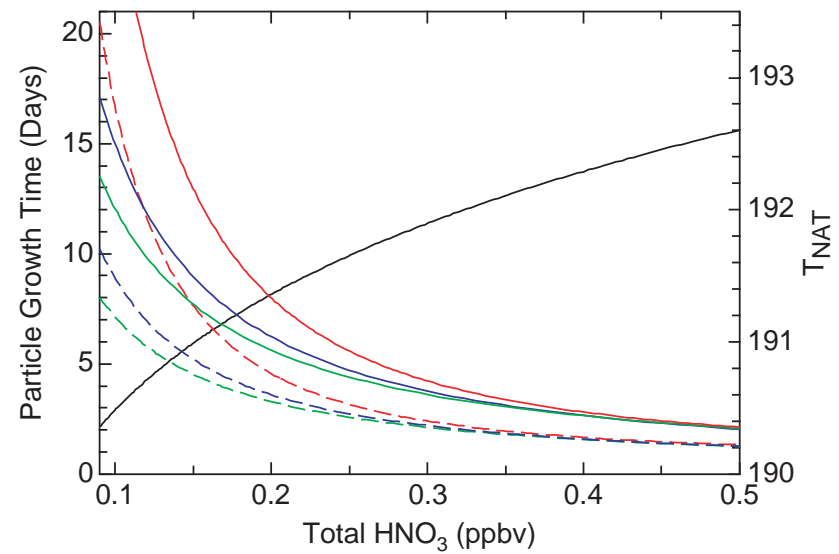

Fig. 5. NAT particle growth times plotted as a function of available gas-phase $\mathrm{HNO}_{3}$ using the model described in Appendix A. The calculations assume a pressure of $80 \mathrm{hPa}$ and the observed water vapor mixing ratio of $3.4 \mathrm{ppmv}$. Green, blue and red lines represent growth times at 187,188 and $189 \mathrm{~K}$, respectively. The time represents that needed for a $0.1 \mu \mathrm{m}$ diameter particle to grow to a $2 \mu \mathrm{m}$ (dashed line) or $3 \mu \mathrm{m}$ (solid line) diameter NAT particle. The NAT saturation temperature is shown as the black solid line.

during this period (Figs. 6 and 7). This difference in trajectory length indicates that nucleation is not localized geographically, for example, near a convectively active region. Particles that never reach the background particle size during the 15-day back trajectory encountered NAT subsaturated air, as indicated by the $\mathrm{S}_{\mathrm{NAT}}$ and particle diameter histories shown in Fig. 7. Since particle histories are calculated backwards in time, the particle size increases when $\mathrm{S}_{\mathrm{NAT}}>1$. Hence, the back trajectory calculations cannot explain the formation of these particles. Furthermore, the particles observed on 29 January (Fig. 2) have back trajectories that leave the tropics after $\sim 6$ days, somewhat before the particles reach background sizes. In this case, the departure of the trajectories from the tropics after 6 days is uncertain because the air is moving along an anticyclonic pathway from higher latitudes. The particles were located near the edge of the anticyclone, and the location of the anticyclone boundary in the analyses used for the trajectories is very uncertain. It is entirely plausible that the anticyclone was actually slightly further north, in which case the particles would have remained in the zonal westerly tropical flow.

\section{Particle nucleation}

The nucleation process for tropical NAT particles cannot be unambiguously identified. However, it is known that all available particles do not nucleate to form NAT, because the tropical NAT particles are collocated with a large population of background particles, assumed to be primarily composed of sulfate. This background aerosol, observed separately 


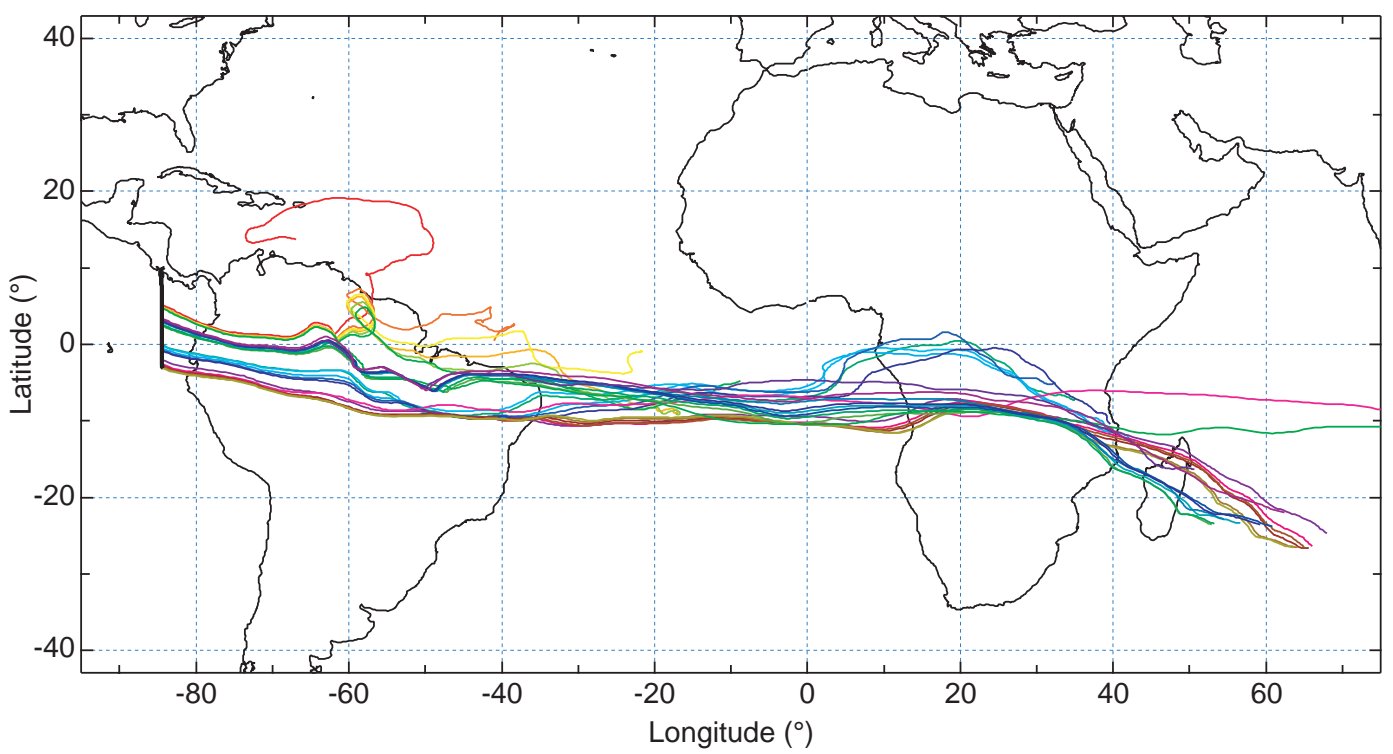

Fig. 6. Fifteen-day particle back trajectories for particles observed under NAT supersaturated conditions ( $\left.\mathrm{S}_{\mathrm{NAT}}>1\right)$ during the flight on 27 January 2004 (Fig. 3). On this day, the WB-57F aircraft flew out and back along a track due south from San Jose, Costa Rica. The flight track is shown in black. Individual trajectories are distinguished by color. Note that some particles travel more than $15000 \mathrm{~km}$ between the time of observation in the tropical eastern Pacific Ocean and their point of origin in the Indian Ocean.

on both flights with an optical particle counter (Appendix B), show concentrations of about $10 \mathrm{~cm}^{-3}$ and mode diameters near $0.1 \mu \mathrm{m}$, which are typical of the lower stratosphere (Brock et al., 1995). If tropical NAT particles nucleate on background sulfate particles, fewer than 1 in $10^{5}$ participate. This small fraction of NAT particles was also found in the Arctic winter vortex (Fahey et al., 2001). In this previous case, the nucleation process, which remains unsolved, might include seeding by a mother cloud, heterogeneous nucleation of sulfate or meteoritic material, and cosmic ray activity (Tabazadeh et al., 2001; Dhaniyala et al., 2002; Fueglistaler, 2002; Drdla et al., 2003; Voigt et al., 2005; Yu, 2004).

Nucleation of tropical NAT particles by a mother cloud seems highly unlikely because of the requirement for ice saturation conditions above the NAT growth region (Dhaniyala, 2002; Fueglistaler, 2002). However, nucleation could occur stochastically in a homogeneous process possibly aided by cosmic rays (Yu, 2004; Carslaw et al., 2002), or in a heterogeneous process involving nuclei or inclusions of special composition (Bogdan et al., 2003; Drdla et al., 2003). A recent study of large NAT particles in polar regions concludes that nucleation on meteoritic inclusions offers the most plausible option (Voigt et al., 2005). Because meteoritic material is ubiquitous in the stratosphere (Cziczo et al., 2001), a similar nucleation process would be possible in the tropics.

What is known is that tropical NAT particles nucleate in air very similar in composition and recent history to the air in which they were observed. This follows simply from the knowledge that particles sediment small distances when sizes remain below a few $\mu \mathrm{m}$ in diameter and that particle trajec- tories during growth necessarily remain close to the tropical tropopause in NAT supersaturated conditions. Thus, air sampled with the particles observed here likely also contained other examples of background particles that could nucleate NAT.

\section{Implications}

Several important implications follow from the observations of tropical NAT particles and inferred formation conditions. First, it seems reasonable to speculate that the tropical and polar NAT particles nucleate with a common process since low NAT particle concentrations are observed in both regions. This common process would likely involve a small number of special particles with the ability to nucleate NAT, or require that the homogeneous nucleation rate be slow enough to activate only a small fraction of the available sulfate aerosol over the growth times allowed by tropical and polar trajectories. Thus, the definitive identification of the tropical NAT particle nucleation process is likely to further our understanding of particle nucleation processes in the polar regions.

Second, ice particles might form via a similar nucleation process and with the same nuclei as tropical NAT particles. Theoretically, there seems nothing to distinguish the microphysics of NAT nucleation from that of ice that would suggest that NAT would form and not ice when both are supersaturated. For example, their respective saturation temperatures typically differ by less than $2 \mathrm{~K}$ near the tropopause. 
A dilute population of ice particles could grow and sediment near the tropical tropopause and, thereby, represent a new contributing pathway to stratospheric dehydration.

Third, the observations and trajectory analyses of tropical NAT particles imply that these particles might be a common feature of the tropical tropopause region. As a test, we used a forty-day back trajectory ensemble initiated globally in the deep tropics in the 10 December 1995-20 January 1996 period (Jensen and Pfister, 2004). Tropopause temperatures are lowest in northern hemisphere winter and, hence, most favorable for NAT formation. The analysis shows that $10 \%$ of air masses between $5^{\circ} \mathrm{S}$ and $5^{\circ} \mathrm{N}$ latitude and near the tropopause were supersaturated with respect to NAT $\left(S_{\mathrm{NAT}}>1\right)$ for periods of at least 6 days or longer. Since 6 days is the approximate time required for particles to grow to detectable sizes under conditions reported here (Fig. 7), we estimate that approximately $10 \%$ of air masses in the deep tropics could contain NAT particles with the observed properties in the December/January period. We also note that this may be a conservative estimate, since particles were observed over an $1100 \mathrm{~km}$ region on 2 out of 3 southbound flights from Costa Rica during this study.

Fourth, at the number concentrations and sizes observed, tropical NAT particles will not be observable in satellite extinction measurements. Calculated extinction values are near $1 \cdot 10^{-6} \mathrm{~km}^{-1}$ at $525 \mathrm{~nm}$, which is much less than the background aerosol extinction and below reasonable detection thresholds for a thin aerosol layer near the tropopause. Previous inferences of tropical NAT particles are based on much larger extinction values $\left(>0.01 \mathrm{~km}^{-1}\right)$ (Hervig and McHugh, 2002) that are not consistent with the low $\mathrm{HNO}_{3}$ abundances observed in situ during this and previous studies (Jensen and Drdla, 2002).

\section{Appendix A}

\section{Model to calculate NAT particle growth times}

We use a standard diffusional growth law (Pruppacher and Klett, 1978) in the form

$$
\begin{aligned}
& G \equiv a \frac{d a}{d t}= \\
& \frac{M_{n}}{\rho} \mu \cdot \kappa D_{n} \beta_{n} \frac{p_{n}-p_{\mathrm{NAT}}}{k T}, \beta_{n}=\frac{1}{1+4 \kappa D_{n} /\left(\alpha u_{n} a\right)}
\end{aligned}
$$

to calculate the time an ensemble of monodisperse particles composed of NAT needs to grow from an initial radius $a_{i}$ to a final radius $a_{f}$ at a fixed temperature $T, \mathrm{HNO}_{3}$ partial pressure $p_{n}, \mathrm{H}_{2} \mathrm{O}$ partial pressure $p_{w}$, and air pressure $p$ of $80 \mathrm{hPa}$. In Fig. 5 we have assumed an $\mathrm{H}_{2} \mathrm{O}$ volume mixing ratio of 3.4 ppmv and vary the total $\mathrm{HNO}_{3}$ concentration.

Here, $t$ is the time, $a$ is the particle radius, $M_{n}$ is the mass of an $\mathrm{HNO}_{3}$ molecule, $\rho=1.62 \mathrm{~g} / \mathrm{cm}^{3}$ is the NAT mass density, $\mu=\left(3 M_{w}+M_{n}\right) / M_{n}$ is a flux correction factor with the

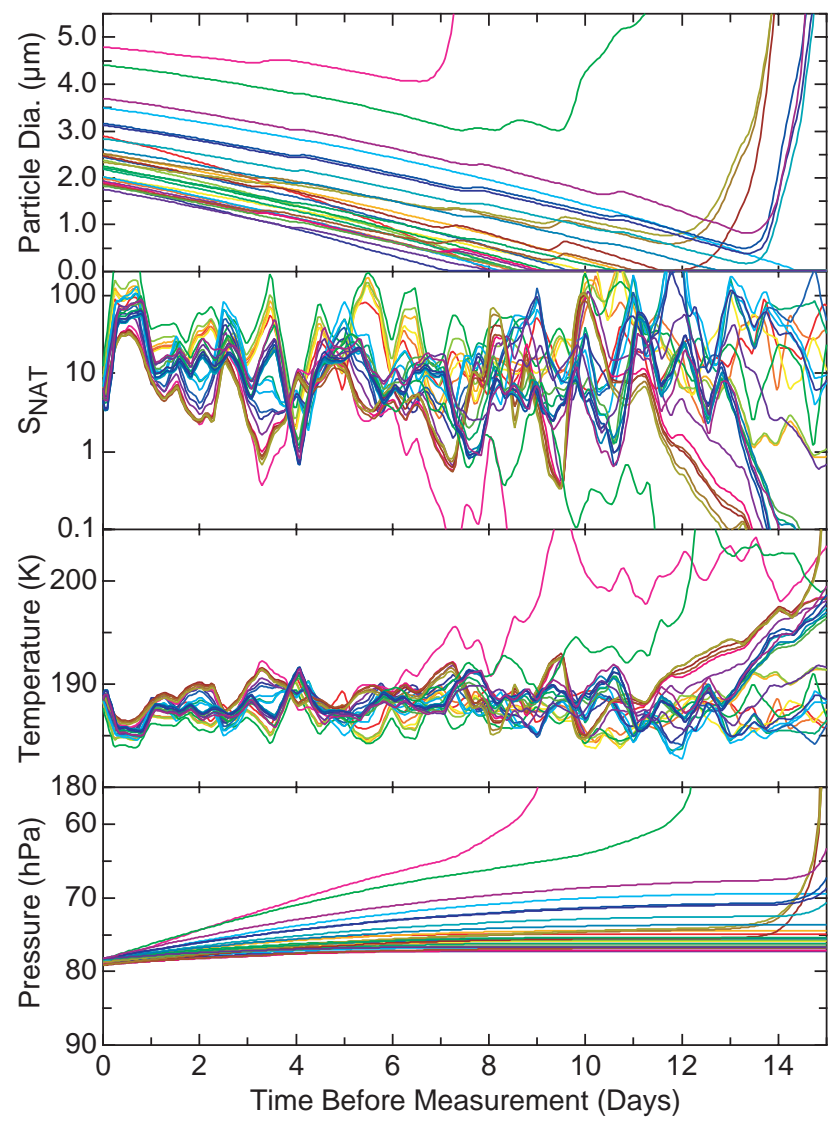

Fig. 7. Particle size and growth conditions along fifteen-day back trajectories that were initiated at locations where particles were observed on the flight on 27 January 2004 (Fig. 3). Individual particles are distinguished by color coding according to the same scheme in Fig. 6. Throughout the trajectory period, the particles are growing (forward in time) because they largely remain in air that is supersaturated with respect to NAT $\left(\mathrm{S}_{\mathrm{NAT}}>1\right)$ ). Temperatures of $190 \mathrm{~K}$ or less are characteristic of the tropical tropopause region. Increasing pressure values indicate that the particles are sedimenting as they grow.

mass $M_{w}$ of an $\mathrm{H}_{2} \mathrm{O}$ molecule, $\kappa=1.61$ is the capacitance accounting for the non-spherical shape of NAT particles, $D_{n}(p, T)$ is the diffusion coefficient for $\mathrm{HNO}_{3}$ molecules in air, $\beta_{n}$ is a correction factor accounting for gas kinetic effects that become important within about one molecular mean free path around the particle surface, $p_{\mathrm{NAT}}\left(p_{w}, T\right)$ is the NAT saturation vapor pressure (Hanson and Mauersberger, 1988), and $k$ is the Boltzmann constant. The factor $\mu$ takes into account that one impinging $\mathrm{HNO}_{3}$ molecule is accompanied by three $\mathrm{H}_{2} \mathrm{O}$ molecules to form NAT at the particle surface, implying that $\mathrm{H}_{2} \mathrm{O}$ molecules equilibrate with the particles much quicker than $\mathrm{HNO}_{3}$ due to their much higher gas phase abundance. In the expression for $\beta_{n}, \alpha=1$ is the deposition coefficient and $u_{n}$ is the thermal speed of $\mathrm{HNO}_{3}$ molecules. 
The growth equation is solved explicitly according to

$a(t+\Delta t)=\sqrt{a^{2}(t)+2 G(t) \Delta t}$

using a time step $\Delta t=30 \mathrm{~s}$ with $a(t=0)=a_{i}$ until $a_{f}$ is reached. As only a small fraction of the $\mathrm{HNO}_{3}$ molecules is in the particle phase, significant depletion of the gas phase does not occur and $p_{n}$ approximately equals the total $\mathrm{HNO}_{3}$ pressure.

\section{Appendix B}

\section{Supporting measurements}

Ambient temperature was derived using static pressure, pitot pressure, and total temperature observed with external aircraft probes. Water vapor was measured using an open-path laser light absorption method (May, 1998). Ice water content was derived from the difference between total water and water vapor, measured via Lyman- $\alpha$ fluorescence (Weinstock et al., 1994). Sulfate aerosol number density and size distributions were measured using an optical particle counter (Wilson et al., 1992). The vertical profile of temperature near the aircraft and tropopause height were derived using a passive microwave temperature profiler (Denning et al., 1989). Water vapor profiles shown in Fig. 4 were measured using a tunable diode laser balloon sonde hygrometer (Hagan et al., 2004).

Acknowledgements. We appreciate the efforts of the NASA WB-57F air and ground crews, access to the SHADOZ dataset (http://croc.gsfc.nasa.gov/shadoz), and discussions with D. M. Murphy, Th. Peter, O. B. Toon, and C. Voigt. We also acknowledge J. C. Wilson for advice on the NOAA CIMS inlet design. The NASA Upper Atmosphere Research Program and the SCOUT-O3 project funded by the European Commission provided partial support of this research. Work performed by R. L. Herman and M. J. Mahoney at the Jet Propulsion Laboratory, California Institute of Technology, was done under contract with the National Aeronautics and Space Administration.

Edited by: R. MacKenzie

\section{References}

Baker, M. B.: Cloud microphysics and climate, Science, 276, 10721078, 1997.

Bogdan, A., Kulmala, M., MacKenzie, A. R., et al.: Study of finely divided aqueous systems as an aid to understanding the formation mechanism of polar stratospheric clouds: Case of $\mathrm{HNO}_{3} / \mathrm{H}_{2} \mathrm{O}$ and $\mathrm{H}_{2} \mathrm{SO}_{4} / \mathrm{H}_{2} \mathrm{O}$ systems, J. Geophys. Res., 108(D10), 4303, doi:10.1029/2002JD002605, 2003.

Brock, C. S., Hamill, P., Wilson, J. C., et al.: Particle formation in the upper tropical troposphere - A source of nuclei for the stratospheric aerosol, Science, 270, 1650-1653, 1995.
Carslaw, K. S., Clegg, S. L., and Brimblecombe, P.: A thermodynamic model of the system $\mathrm{HCl}-\mathrm{HNO}_{3}-\mathrm{H}_{2} \mathrm{SO}_{4}-\mathrm{H}_{2} \mathrm{O}$, including solubilities of $\mathrm{HBr}$, from $<200 \mathrm{~K}$ to $328 \mathrm{~K}$, J. Phys. Chem., 99, 11 557-11 574, 1995.

Carslaw, K. S., Harrison, R. G., and Kirkby, J.: Cosmic rays, clouds, and climate, Science, 298, 1732-1737, 2002.

Cziczo, D. J., Thomson, D. S., and Murphy, D. M.: Ablation, flux, and atmospheric implications of meteors inferred from stratospheric aerosol, Science, 291, 1772-1775, 2001.

Davies, S., Mann, G. W., Carslaw, K. S., et al.: 3-D microphysical model studies of Arctic denitrification: Comparison with observations, Atmos. Chem. Phys., 5, 3093-3109, 2005.

Denning, R. F., Guidero, S. L., Parks, G. S., et al.: Instrument description of the airborne microwave temperature profiler, J. Geophys. Res., 94, 16757-16 765, 1989.

Dhaniyala, S., McKinney, K. A., and Wennberg, P. O.: Lee-wave clouds and denitrification of the polar stratosphere, Geophys. Res. Lett., 29, 1322, doi:10.1029/2001GL013900, 2002.

Drdla, K., Schoeberl, M. R., and Browell, E. V.: Microphysical modeling of the 1999-2000 Arctic winter: 1. Polar stratospheric clouds, denitrification, and dehydration, J. Geophys. Res., 108, 8312, doi:10.1029/2001JD000782, 2003.

Fahey, D. W., Gao, R. S., Carslaw, K. S., et al.: The detection of large $\mathrm{HNO}_{3}$-containing particles in the winter arctic stratosphere, Science, 291, 1026-1031, 2001.

Fueglistaler, S.: NAT-rock formation by mother clouds: A microphysical model study, Atmos. Chem. Phys., 2, 93-98, 2002.

Gao, R. S., Richard, E. C., Popp, P. J., et al.: Observational evidence for the role of denitrification in Arctic stratospheric ozone loss, Geophys. Res. Lett., 28, 2879-2882, 2001.

Gao, R. S., Popp, P. J., Fahey, D. W., et al.: Evidence that nitric acid increases relative humidity in low-temperature cirrus clouds, Science, 303, 516-520, 2004.

Hagan, D. E., Webster, C. R., Farmer, C. B., et al.: Validating AIRS upper atmosphere water vapor retrievals using aircraft and balloon in situ measurements, Geophys. Res. Lett., 31, L21103, doi:10.1029/2004GL020302, 2004.

Hamill, P. and Fiocco, G.: Nitric acid aerosols at the tropical tropopause, Geophys. Res. Lett., 15, 1189-1192, doi:10.1029/88GL03593, 1988.

Hanson, D. and Mauersberger, K.: Laboratory studies of the nitricacid trihydrate - Implications for the south polar stratosphere, Geophys. Res. Lett., 15, 855-858, 1988.

Hervig, M. and McHugh, M.: Tropical nitric acid clouds, Geophys. Res. Lett., 29, 1125, doi:10.1029/2001GL014271, 2002.

Heymsfield, A. J. and McFarquhar, G. M.: On the high albedos of anvil cirrus in the tropical Pacific warm pool: Microphysical interpretations from CEPEX and from Kwajalein, Marshall Islands, J. Atmos. Sci., 53, 2424-2451, 1996.

Jensen, E. J., Toon, O. B., Pfister, L., and Selkirk, H. B.: Dehydration of the upper troposphere and lower stratosphere by subvisible cirrus clouds near the tropical tropopause, Geophys. Res. Lett., 23, 825-828, doi:10.1029/96GL00722, 1996.

Jensen, E. J. and Drdla, K.: Nitric acid concentrations near the tropical tropopause: Implications for the properties of tropical nitric acid trihydrate clouds, Geophys. Res. Lett., 29, 2001, doi:10.1029/2002GL015190, 2002.

Jensen, E. J. and Pfister, L.: Transport and freeze-drying in the tropical tropopause layer, J. Geophys. Res., 109, D02207, 
doi:10.1029/2003JD004022, 2004.

Kley, D., Russell, J. M., and Phillips, C.: SPARC assessment of upper tropospheric and stratospheric water vapor, WCRP No. 113, WMO/TD - No. 1043, SPARC Report No. 2, 2000.

Kondo, Y., Toon, O. B., Irie, H., et al.: Uptake of reactive nitrogen on cirrus cloud particles in the upper troposphere and lowermost stratosphere, Geophys. Res. Lett., 30, 1154, doi:10.1029/2002GL016539, 2003.

Lawrence, M. G. and Crutzen, P. J.: The impact of cloud particle gravitational settling on soluble trace gas distributions, Tellus, 50B, 263-289, 1998.

Luo, B. P., Peter, Th., Wernli, H., et al.: Ultrathin Tropical Tropopause Clouds (UTTCs): II. Stabilization mechanisms, Atmos. Chem. Phys., 3, 1093-1100, 2003.

Mann, G. W., Davies, S., Carslaw, K. S., and Chipperfield, M. P.: Factors controlling Arctic denitrification in cold winters of the 1990s, Atmos. Chem. Phys., 3, 403-416, 2003.

Marcy, T. P., Gao, R. S., Northway, M. J., et al.: Using chemical ionization mass spectrometry for detection of $\mathrm{HNO}_{2}, \mathrm{HCl}$, and $\mathrm{ClONO}_{2}$ in the atmosphere, Int. J. Mass Spectrom., 243, 63-70, 2005.

May, R. D.: Open-path, near-infrared tunable diode laser spectrometer for atmospheric measurements of $\mathrm{H}_{2} \mathrm{O}$, J. Geophys. Res., 103, 19 161-19 172, 1998.

McFarquhar, G. M., Heymsfield, A. J., Spinhirne, J., and Hart, B.: Thin and subvisual tropopause tropical cirrus: Observations and radiative impacts, J. Atmos. Sci., 57, 1841-1853, 2000.

Murphy, D. M., Fahey, D. W., Proffitt, M. H., et al.: Reactive nitrogen and its correlation with ozone in the lower stratosphere and upper troposphere, J. Geophys. Res., 98, 8751-8773, 1993.

Neuman, J. A., Gao, R. S., Schein, M. E., et al.: A fast-response chemical ionization mass spectrometer for in situ measurements of $\mathrm{HNO}_{3}$ in the upper troposphere and lower stratosphere, Rev. Sci. Inst., 71, 3886-3894, 2000.

Neuman, J. A., Gao, R. S., Fahey, D. W., et al.: In situ measurements of $\mathrm{HNO}_{3}, \mathrm{NO}_{\mathrm{y}}, \mathrm{NO}$, and $\mathrm{O}_{3}$ in the lower stratosphere and upper troposphere, Atmos. Environ., 35, 5789-57597, 2001.

Northway, M. J., Gao, R. S., Popp, P. J., et al.: An analysis of large $\mathrm{HNO}_{3}$-containing particles sampled in the Arctic stratosphere during the winter of 1999/2000, J. Geophys. Res., 107, 8298, doi:10.1029/2001JD001079, 2002.
Peter, Th., Luo, B. P., Wirth, M., et al.: Ultrathin Tropical Tropopause Clouds (UTTCs): I. Cloud morphology and occurrence, Atmos. Chem. Phys., 3, 1083-109, 2003.

Popp, P. J., Gao, R. S., Marcy, T. P., et al.: Nitric acid uptake on subtropical cirrus cloud particles, J. Geophys. Res., 109, D06302, doi:10.1029/2003JD004255, 2004.

Pruppacher, H. R. and Klett, J. D.: Microphysics of Clouds and Precipitation, Reidel Publishing Co., Holland, 1978.

Rex, M., Harris, N. R. P., von der Gathen, P., et al.: Prolonged stratospheric ozone loss in the 1885/96 Arctic winter, Nature, 389, 835-838, 1997.

Ström, J., Seifert, M., Kärcher, B., et al.: Cirrus cloud occurrence as function of ambient relative humidity: a comparison of observations obtained during the INCA experiment, Atmos. Chem. Phys., 3, 1807-1816, 2003.

Tabazadeh, A.: Role of the stratospheric freezing belt in denitrification, Science, 291, 2591-2594, 2001.

Thompson, A. M., Witte, J. C., Oltmans, S. J., and Schmidlin, F. J.: SHADOZ (Southern Hemisphere ADditional OZonesondes): A tropical ozonesonde-radiosonde network for the atmospheric community, Bull. Am. Meteorol. Soc., 85, 1549-1564, 2004.

Voigt, C., Schreincer, J., Kohlmann, A., et al.: Nitric acid trihydrate (NAT) in polar stratospheric clouds, Science, 290, 1756-1758, 2000.

Voigt, C., Schlager, H., Luo, B. P., et al.: Nitric acid trihydrate (NAT) formation at low NAT supersaturations, Atmos. Chem. Phys., 5, 1371-1380, 2005.

Weinstock, E. M., Hintsa, E. J., Dessler, A. E., et al.: New fastresponse photofragment fluorescence hygrometer for use on the NASA ER-2 and the Perseus remotely piloted aircraft, Rev. Sci. Instrum., 65, 3544-3554, 1994.

Wilson, J. C., Stolzenburg, M. R., Clark, W. E., et al.: Stratospheric sulfate aerosol in and near the northern hemisphere polar vortex: The morphology of the sulfate layer, multimodal size distributions, and the effect of denitrification, J. Geophys. Res., 97, 7997-8013, 1992.

Yu, F.: Formation of large NAT particles and denitrification in polar stratosphere: Possible role of cosmic rays and effect of solar activity, Atmos. Chem. Phys., 4, 2273-2283, 2004. 